\title{
A pilot study into ecological burning in forests as part of a species conservation plan
}

\author{
MATTHEW W. PEARSON \\ College of Science and Sustainability, Faculty of Health Medical and Applied Sciences, University of Central Queensland. Mackay-Ooralea Campus; \\ Building 1, 171 Boundary Road Ooralea Mackay, Queensland 4740, Australia. Tel.: +61-4-1980 9288, email: m.pearson@cqumail.com
}

Manuscript received: 25 September 2020. Revision accepted: 15 February 2021.

\begin{abstract}
Pearson MW. 2021. A pilot study into ecological burning in forests as part of a species conservation plan. Biodiversitas 22: 1296-1303. Fire management and the process of managing communities has become an increasingly topical subject due to recent events. The role of fire for fuel reduction with areas set aside for conservation may not be compatible as a seed recruitment tool for Allocasuarina robusta. Presently, fire as a recruitment tool on A. robusta is not well understood. The pilot study aims to examine the latent seedbank ability to contribute to the conservation of A. robusta when ecological burning is part of a fire management plan. The investigation examined the soil seed bank beneath A. robusta before and after an ecological burn as a greenhouse experiment. The experiment results demonstrated that a diverse range of species responds to a fire that may out-compete the seed recruitment from $A$. robusta. The results indicate that $A$. robusta may not be recruiting through seed. Competition appears to be a factor that may limit the ability of $A$. robusta to recruit from seed.
\end{abstract}

Keywords: Germination, restoration, seed bank, fire

\section{INTRODUCTION}

Anthropogenic land-use changes have altered vegetation communities directly or indirectly, resulting in changes to natural regimes, i.e. flooding or fire (Woolfrey and Ladd 2001; Bradford et al. 2008). Intensive agriculture in open Eucalypt woodlands and low-lying heath has reduced the extent and abundance of diversity in the South Australian Mount Lofty Ranges with 236 plant species listed as threatened or rare (Armstrong et al. 2003; Quarmby 2016). Changes to hydrological regimes and seasonal fire cycles facilitate the establishment of invasive species, which further alter hydrology and increase the effects of salinization. Since European settlement, $25 \%$ of swamps have disappeared, $49 \%$ represent degraded swamps, and 26\% are relatively intact (Department for Environment and Heritage 2007). Some hydrophyte/ geophyte species depend on specific hydrological or fire regimes, and as a consequence, when these environmental processes change, they become a threatened species (Bickford et al. 2008).

Since European settlement, the South Australian landscape has changed dramatically (Beinke et al. 2011; Morgan et al. 2020). A. robusta is a threatened species now restricted in distribution to $172 \mathrm{~km}^{2}$ in the Mount Lofty Ranges, in the south-eastern region of South Australia (Quarmby 2016). Most A. robusta populations reside in small roadside reserves, which are subject to ongoing disturbance (Quarmby 2016). Presently, environmental rehabilitation is occurring to restore hydrological regimes in Myponga Creek catchment, within the range of $A$. robusta (Bickford et al. 2008; Bradford et al. 2008; Bachmann and Farrington 2016). The works aim to restore natural water regimes and restrict water movement to enable the water to meander across the landscape by creating localized flood-out areas to improve biodiversity and restore a more natural hydrological regime (Beinke et al. 2011).

Allocasuarina robusta, like other Allocasuarina, is considered serotinous species with seed released following a fire (Abbott 1984). However, fire-related germination can be variable and may reduce if a fire is too intense, and the fruit incurs heat shock (Ma et al. 2017). Mature Allocasuarina can reshoot from lignotubers after the mainstem's death (Ooi et al. 2007). However, the ability to regenerate from lignotubers requires augmentation with seeds to ensure long-term population viability (Wellington and Noble 1985; Ooi et al. 2007). Recovery for A. robusta may be achieved through ecological burning to initiate dormant seed release from fruit along the branches (Gtinster 1994; Ooi et al. 2007). However, we still do not understand if a fire is a useful management tool to aid the recovery process. Fire is one of the main drivers for population recruitment, as is the case for many other Allocasurina species.

The presence of fire is an environmental variable that can select species based on their tolerance towards a fire (Ma et al. 2017; Sagra et al. 2019; Alahakoon et al. 2020; Tangney et al. 2020). Current natural resource management practice use of fire does not reflect past fire events (Sagra et al. 2019). Sagra et al. (2019) describes current management practices/policies, lead to increased fire intensities and fuel loads, promoting more severe fire events. The regeneration of vegetation selected for fire tolerance will appear as basal or lignotubers or serotinous seeders (Ooi et al. 2007; Lamont and Bellingham 2020). 
How fire affects, the breeding system of a species would simulate or initiate regenerations from seed or through tubers (Alahakoon et al. 2020). Changes to the fire regimes described by Sagra et al. (2019) can lead to changes in the ecosystem process. Alahakoon et al. (2020) and Sagra et al. (2019) identify how fire applied for landscape management purposes can further exacerbate species selection from a fire as alluded to by Ma et al. (2017). The role of an ecological burn and the impact which the fire would have on a species is not well understood (Le Breton et al. 2019). An ecological burn aims to optimize natural regeneration by understanding population dynamics (Le Breton et al. 2019). The same can equally apply to understanding the parental role of serotinous species for seed recruitment (Lamont et al. 2020). When seed released or dormancy broken from a fire, the recruitment process requires an environment with greater resource availability and reduced resource competition (Lamont and Bellingham 2020; Tangney et al. 2020).

Lamont and Bellingham (2020) review discusses the role of recruitment from serotinous seeders and the indices to measure serotiny. However, fire tolerance and recovery identified as two different entities by Chick et al. (2018) as the measuring of fire intensity is through several parameters with the temperature being one parameter. Understanding the interrelationship with temperature can be vital; it will directly impact the species survival (Cochrane 2020). The investigation aims to test the effect of an ecological burn on $A$. robusta by determining if the latent soil seed bank supports seed recruitment of $A$. robusta.

\section{MATERIALS AND METHODS}

\section{Study species}

The climatic conditions $A$. robusta favor are the Fleurieu Peninsula's wettest parts (Department for Environment and Heritage 2007). The Fleurieu Peninsula has a temperate climate with moderately wet winters and hot, dry summers (Armstrong et al. 2003). Rainfall in the Fleurieu Peninsula can range from 400 to $1000 \mathrm{~mm}$ depending on altitude and aspect (Armstrong et al. 2003). A. robusta grows on soils described by the Department for Environment and Heritage (2007) as infertile acidic soils associated with peat bog. The soil types range from mottled yellow ironstone soils, gravelly duplex soils and sandy glacial outwash soils (Department for Environment and Heritage 2007). A. robusta occurs on sandy glacial outwash soils at Hindmarsh Tiers (Bickford et al. 2008).

Allocasuarina robusta occurs in the Kanmantoo bioregion, which includes the southern Mount Lofty Ranges, Fleurieu Peninsula and Kangaroo Island (Department for Environment and Heritage 2007). The Fleurieu Peninsula contains Eucalyptus open forests and woodlands. The habitat description for A. robusta is the peripheries of wetlands where the mesophytes and hydrophytes meet. The critically endangered Fleurieu Peninsula wetlands communities have legislative protection from the Commonwealth and South Australian state government (Department for Environment and Heritage 2007).

Allocasuarina robusta a threatened species of the Mount Lofty Ranges described as a monoecious shrub with smooth bark (Jessop and Toelken 1986, Wilson and Johnson 1989). The branchlets and scales leaves of $A$. robusta are glabrous with the immature scale leave appearing to overlap (Wilson and Johnson 1989). The female inflorescences produce aggregate fruit form a $3 \mathrm{~mm}$ long peduncle; these may be sparsely pubescent or sessile on the peduncle (Jessop and Toelken 1986). The seed of $A$. robusta described as a samara with seed ranging in size from 5.5-6.0 mm (Wilson and Johnson 1989). A. robusta stores the seed above ground and then releases seed through an environmental trigger (Jessop and Toelken 1986, Quarmby 2016). Quarmby (2016) recommended an ecological burn for releasing the above-ground stored seed, to facilitate seed recruitment.

Ecological burns occurred in October 2017 and March 2018 at Stipiturus Conservation Park in the Southern Mount Lofty Ranges in South Australia, $11 \mathrm{~km}$ west of Mount Compass. Stipiturus Conservation Park is one of the largest conserved populations of A. robusta (Quarmby 2016). The park's proclamation was to conserve a regenerating swamp and protect threatened species previously; the park was once an agricultural enterprise (Bachmann and Farrington 2016).

\section{Study design}

Soil sampling occurred on $21^{\text {st }}$ October 2017. Four soil samples (diameter $75 \mathrm{~mm}$, depth $100 \mathrm{~mm}$ ) were taken at $500 \mathrm{~mm}$ apart from each of the $18 \mathrm{~A}$. robusta's base. These samples included surface litter that may have retained $A$. robusta seed.

The four soil samples collected underneath each tree was batched into one larger single sample and then mixed and sieved to remove any material more significant than 10 $\mathrm{mm}$ by $10 \mathrm{~mm}$ (i.e., gravel or sticks). The soil was then placed in $400 \mathrm{ml}$ plastic punnets and assigned to a treatment. Each treatment was replicated five times and randomly distributed in a four-block experiment design. The base of a punnet was covered to a depth of $15 \mathrm{~mm}$ using a-sub-sample of soil. Each batched soil sample was assigned a code related to the tree of origin. Punnets were assigned either as controls (126 punnets used) or as one of two manipulative treatment punnets (smoke water [63 punnets used] or direct fire [63 punnets used]), a total of 252 punnets formed the experimental design.

Smoke water was purchased as a commercial product from Sure Gro and applied at the rate of 1-part smoke water to 10 parts water and applied through overhead watering (10L of water used). Smoke water at a rate of 160 $\mathrm{ml} /$ punnet on the day of soil collection was applied.

A direct fire treatment occurred opportunistically from an ecological burn ( $4^{\text {th }}$ October 2017) when the fire jumped containment lines and burnt part of the population. Flame height for the fire was an estimated $3-4 \mathrm{~m}$ with an unknown rate of spread, with all fuel under $20 \mathrm{~mm}$ consumed (fuel at $20 \mathrm{~mm}$ was scorched $5 \mathrm{~mm}$ in from 
around the circumference) with an estimated 10 tonnes/ha of fuel.

Growth chambers modelled on the Enclosed Propagation Bed produced by Sage Horticulture (https://www.sagehort.com.au/propagation-

equipment/propagation-

beds/propagationtrayheatmistenclosure) used to grow the samples. The average temperature was $29.5^{\circ} \mathrm{C}$ (range: $21.2^{\circ} \mathrm{C}-35.1^{\circ} \mathrm{C}$ ), $80 \%$ relative humidity and 13 hours of light per day from PSII globes.

Punnets were observed daily for 100 days to identify germinants to a floristic family.

\section{Statistical analysis}

A one-way ANOVA compares the control to the seed treatment as a response variable and the three treatments (control, smoke, or direct fire) as predictive variables. Minitab Express (Ver. 1.5.2.0) was used to identify relationships between data. EXSTAT Ecology (Addinsoft 2017) with $R$ interface ( $R$ Development Core Team 2010) was used to complete ANOVA Analysis using germinant families, between treatments (fire, or smoke water or control), and monocotyledon and dicotyledon. Data collection occurred for 26 weeks with the statistical analysis performed on week counts of the seed treatments.

\section{RESULTS AND DISCUSSION}

\section{Results}

A total of 281 seeds germinated composed of 163 dicotyledons and 118 monocotyledons (Figure 1).

A single germinant of Allocasuarina sprouted in the fire treatment (Figure 2). Germinates of Cyperaceae and Myrtlaceae were positively associated with treatments of fire or smoke (Figure 2). Other families that benefit from fire include the Leguminosae and to some extent, Dennstaedtaceae. As observed, Dennstaedtaceae can resprout after fire from underground rhizomes and may occur at lower relative abundances after the fire (Figure 2).

Smoke treated seeds had significantly higher germination rates $(\mathrm{F}=2.4499$, $\mathrm{df}=4$, error $=116, \mathrm{P}=$ 0.0009 ) with an average of $10.83 \pm 15.77$ (S.D.) dicotyledons and $12.17+11.74$ (S.D.) monocotyledons. Fire treated seeds had intermediate germination levels an average of $10.50 \pm 8.73$ (S.D.) dicotyledons and $5.17 \pm$ 2.23 (S.D.) monocotyledons. Control seeds had the lowest germination, with $5.67 \pm 4.03$ (S.D.) dicotyledons and 2.33 \pm 1.97 (S.D.) monocotyledons (Figure 4). There was no significant difference in the average number of germinants of dicotyledons and monocotyledons in treatments exposed to fire $(\overline{\mathrm{x}}=3 \pm 0.7 \mathrm{XCI}, \mathrm{P}=0.97)$ or smoke $(\mathrm{P}=0.91)$. The results produced nine dicotyledons families compared to monocotyledons composed of four Families (Figure 3).

The total number of dicotyledons germinated from fire and smoke was the same at the end of the twelve-week trial $(n=65)$.

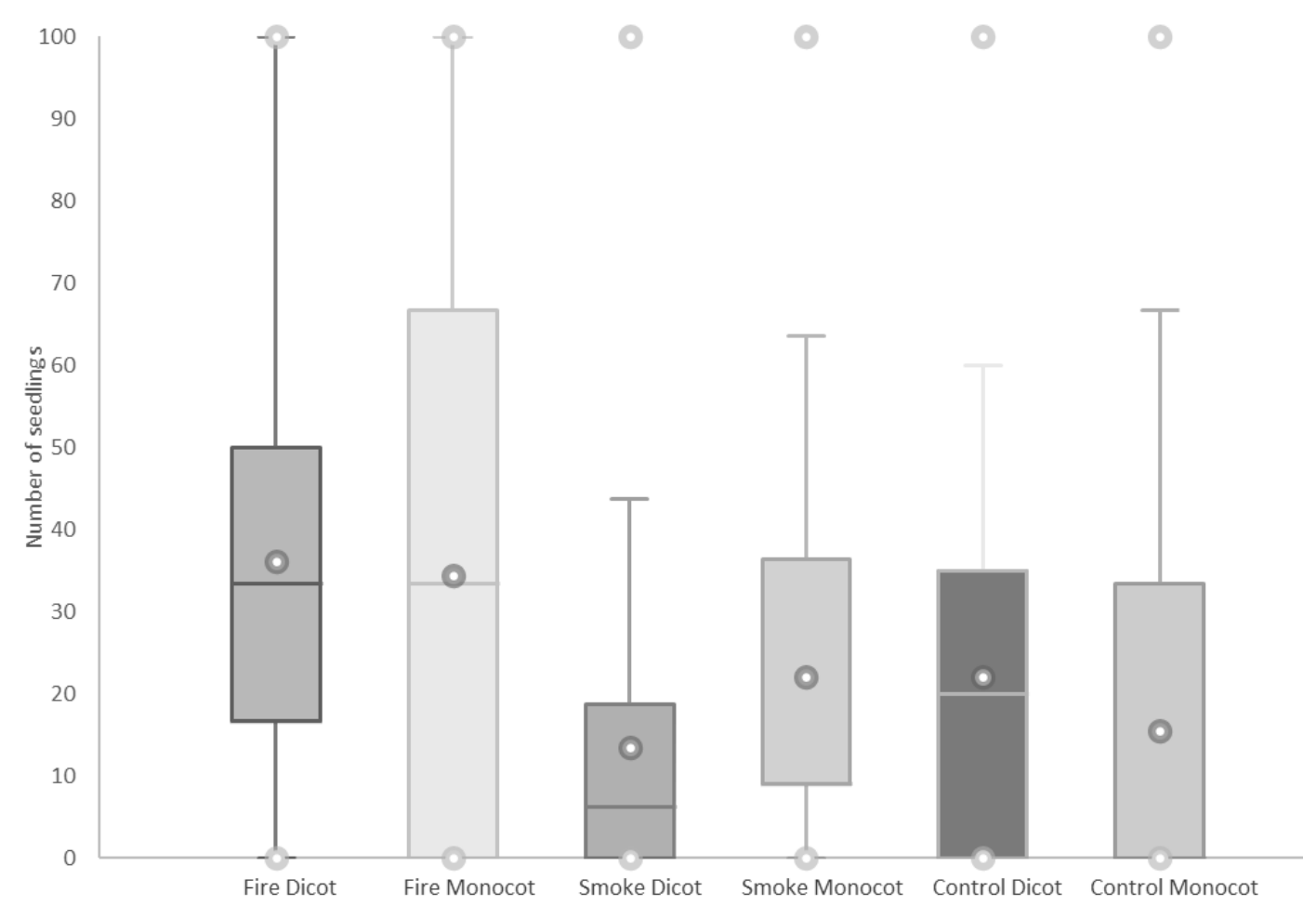

Figure 1. Frequency of germination of $A$. robusta by treatment (Dicot $=$ dicotyledon, Monocot $=$ monocotyledon $)$ 


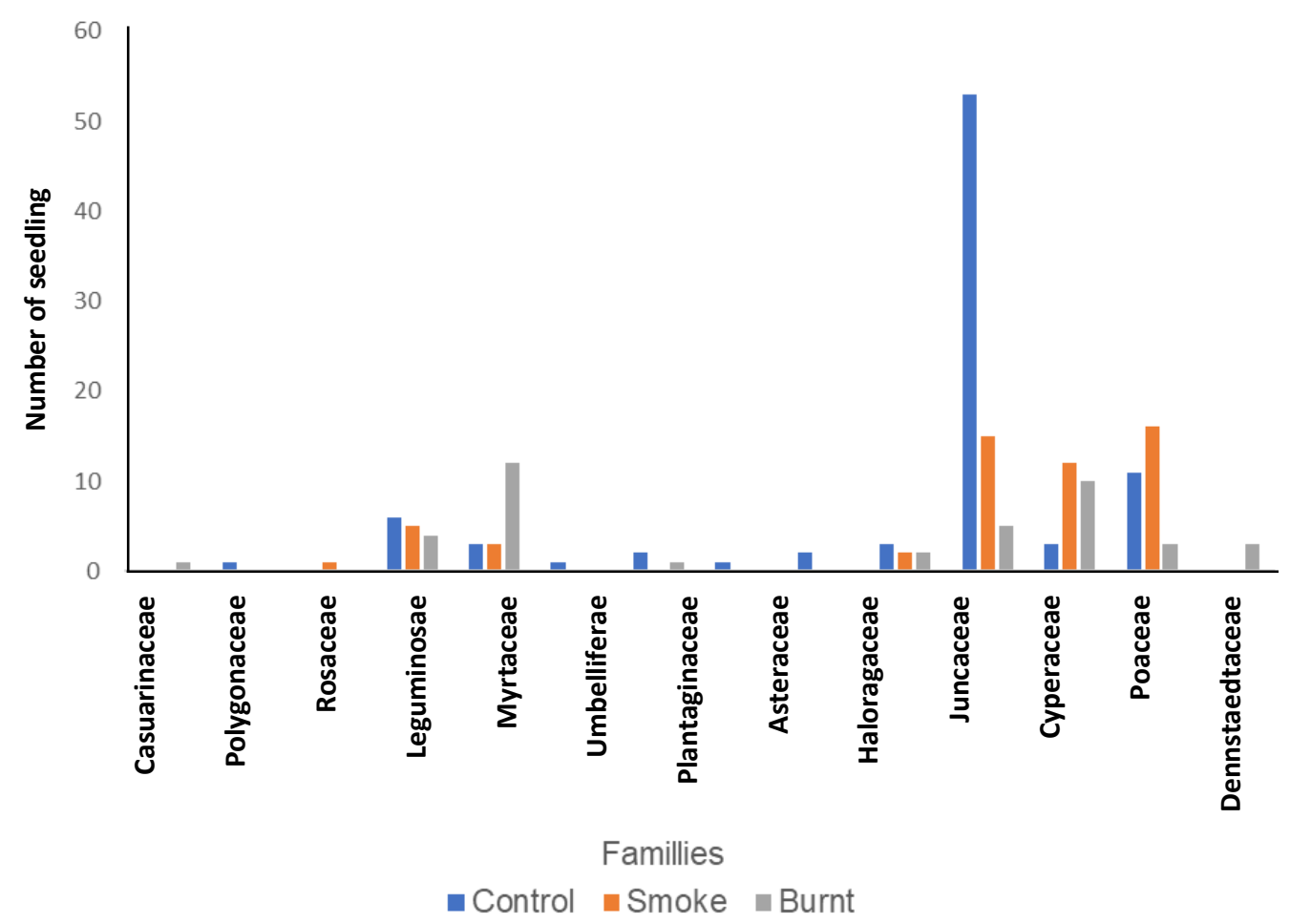

Figure 2. Family frequency of germination from soil samples

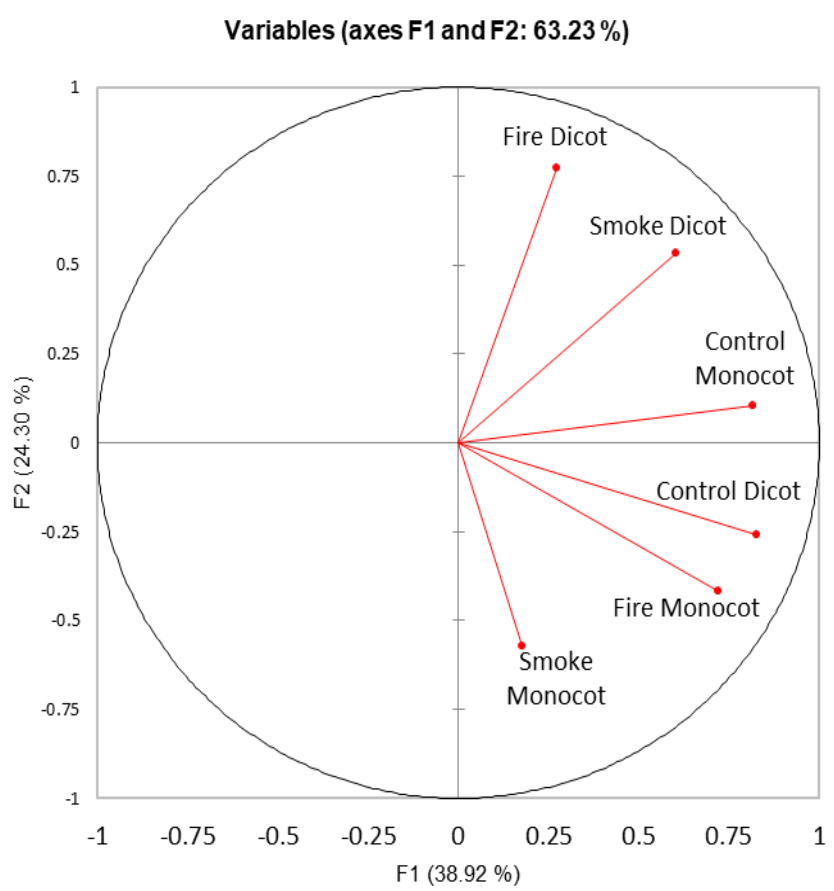

Figure 3. PCA plots of comparison between treatments $($ Dicot $=$ dicotyledon Monocot $=$ monocotyledon $)$.

\section{Discussion}

The study aimed to test the effect of an ecological burn on $A$. robusta and determine whether collecting the latent soil seed bank is an adequate population recruitment tool. When exposed to fire and smoke, the trial indicated that

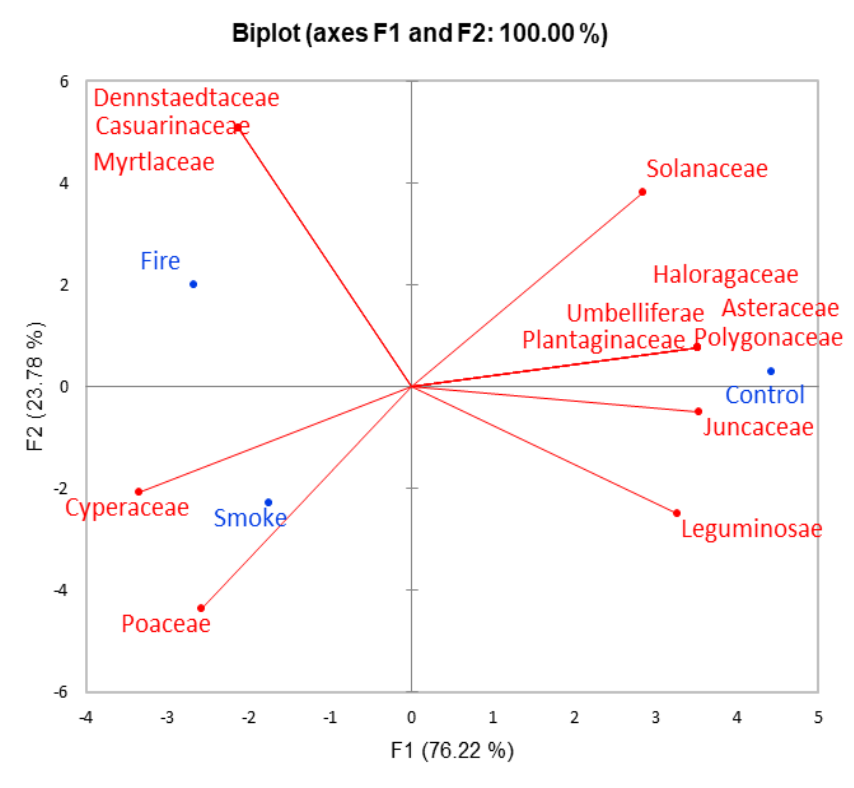

Figure 4: PCA plots of comparison between treatments and Families.

dicotyledons had the highest germination rates (Figure 3). Families that responded positively to the fire included Cyperaceae, Myrtleaceae, and Junaceae (Figure 2). The diversity of vegetation which resulted from the simulated disturbance event is not uncommon as Hodges et al. (2019) 
describe that fire can maintain a rich diversity of forbs and graminoids. Hodges et al. (2019) identify that a misconception can occur that fire will promote vegetation to regenerate vegetatively but from seed recruitment.

From the pilot study, only a single $A$. robusta, germination occurred. Therefore, the effect of fire on $A$. robusta is not apparent as single germination would not be conclusive for addressing the pilot study's aim. In contrast, an investigation involving removing the soil seed bank the germination of threatened flora increased (řehounková et al. 2020). In the investigation involving A. robusta, sitespecific environmental characteristics may stimulate $A$. robusta seed to germination. From pot culture/controlled environment investigation fire may not be a significant driver of germination in $A$. robusta or, the samples may not have included viable $A$. robusta seeds. The single germination of $A$. robusta would fit within the perspective provided by Hodges et al. (2019) concerning seed recruitment not being favored by fire. Instead, vegetative regeneration is more frequent after a fire (Hodges et al. 2019). From the investigation, fire and smoke (Figure 4) indicate that some species will respond to burning. Zirondi et al. (2019) explained that the results from their investigation produced an idiosyncratic response to fire. From the pilot study, fire and smoke responses may relate to the experimental design scale. From the investigation, the results support Zirondi et al. (2019) by showing that fire resistance/tolerance can be an ecological advantage in landscapes shaped by fire.

The lack of $A$. robusta germinants demonstrates a need to identify what mechanism impeded germination. Understanding the lack of germination can relate to experimental design in how the treatment was applied consistently. Consistency and repeatability in the experimental design's pot culture could infer a particular result would occur under a specific condition. A specific result would not be unusual as Wills and Read (2002) 's investigation would support specific conditions that can elicit specific outcomes in regenerating communities when exposed to fire. Possible causes of reduced seed viability include age (Saverimuttu and Westoby 1996), inbreeding depression (Finlay et al. 2017) and competition (Cortina and Maestre 2005). The longevity of serotinous species can reduce viability overtime. In $A$. robusta, the aspect of dormancy related to the aggregate fruit could impact the species ability to recruit from seed. To break the dormancy as Hodges et al. (2019) postulates may not be related to smoke and heat, which may result in little or no impact on seed germination. In arid land species, the two-year-old seed has diminished seed viability (Gtinster 1994). However, the relationship to viability and longevity will vary with location and species, and we do not know how long $A$. robusta seeds are viable nor the age of the seeds in our study (Gtinster 1994; Ma et al. 2017). Competition from other flora and competition from graziers can also reduce seedling survival (Abbott 1984). Grazing can hamper natural recruitment if seedlings are a preferred feed. Further studies were advocated in the past on $A$. robusta to understand the germination process (Quarmby 2016). Quarmby (2016) identified that work is required to understand natural recruitment, and it is plausible that the small populations of $A$. robusta may have reduced breeding fitness.

Previous investigations involving Allocasuarina have not focused on the relationship between germination, fire and environment (Abbott 1984, Gtinster 1994). A. robusta perceived as a serotinous regenerator, can challenge our concepts relating to a species interaction with its natural environment (Abbott 1984). Abbott (1984) study showed that a combination of factors could impact seedling survival either from browsing, the thickness of leaf litter or competition from neighboring plants. Vegetation communities shaped by fire can be affected by fire through the frequency of the fire. Defining or shaping a vegetation community by fire is not based solely on the presence and absence of fire. In an investigation by Le Breton et al. (2019), the inference of fire intensity related to the seed bank interpreted this as another form of selection within a community As a fire increases in frequency or intensity perennial vegetation like A. robusta may not have reached a mature state to develop and store seed for release after a fire event Wills and Read (2002). Unlike Abbott (1984), these environmental conditions went untested, providing future research opportunities on A. robusta. Several other environmental factors relating to the physical environment could impact on the germination of seed following the release of seed, like Chick et al. (2018) identified the moisture and soil nutrient content the soil can play an essential role in the survival of a germinate. Compared to Wills and Read (2002), which identified that different fire intensity thresholds could result in different vegetation associations, a term used to describe this fire intensity on a seed is heat shock. Chick et al. (2018) shared the same hypothesis that fire could become a selective tool depending on fire intensity and frequency.

An environmental factor like heat shock to A. robusta fruit from the fire could form future studies. Heat shock in some species can range from $40^{\circ} \mathrm{C}$ to $80^{\circ} \mathrm{C}$ with the responses being variable between species and within a species (Ma et al. 2017; Dias et al. 2019). Heat shock is part of a physiological dormancy where the cue for germination is not from fire, but the generated heat (Ma et al. 2017; Luna 2020). The influence of heat shock on propagules or initiating the germination is related to several parameters, including the fire intensity, temperature, and spread rate (Dias et al. 2019; Zirondi et al. 2019). The impact of fire on A. robusta will initiate the seed's release from the above-ground seed bank. Some species observed in a vegetation community respond favorably to heat shock effects (Dias et al. 2019). Seed release from the serotinous seeder like A. robusta will compete with seed stored in the soil seed bank that may be more competitive (Zirondi et al. 2019). The results showed only a single $A$. robusta germination occurred, which indicated the possibility that heat shock could play an integral part in A. robusta seed recruitment (Dias et al. 2019[ Le Breton et al. 2019). Zirondi et al. (2019) describes that the fire's impact can change the soil properties, albeit only temporary, which may have selective quality on the germinants' survival. From the investigation conducted, changes in soil 
properties may form an avenue for future investigation. The function of fire considered a factor that shapes Australian vegetation communities, but fire can cause the death of seeds even though others will survive (Zirondi et al. 2019).

The provision of heat shock from a fire and a simulated version of heat shock from boiling water and smoke water may elicit a different result. Ma et al. (2017) described the physiological response related to fire's direct effects on fruit. Compared to the heat shock undertaken by Alahakoon et al. (2020) investigation, which used a comparable method compared to the current investigation. Alahakoon et al. (2020) investigation supported the idea that fire would shape a vegetation community, but this was not replicated by either Luna (2020) investigation or the current investigation. In Luna (2020), the heat shock and the fire intensity related to the seed lens thickness. The results tend to lend themselves towards creating the perception that community that $A$. robusta is a part of a community not driven by fire (Figure 3 ). Alahakoon et al. (2020) investigation reported results where some serotinous species did not respond to a simulated fire and use smoke water as an alternative to fire. Like in Alahakoon et al. (2020), which identified further investigation is required to understand fire/smoke's role in simulating seed germination. The current investigation supports Alahakoon et al. (2020) conclusion, but in particular, the role of fire/smoke to initiate the germination of $A$. robusta requires further investigation. The importance of the interrelationships demonstrated by Cochrane (2020) investigation showed the importance of co-occurring species when changes in the environmental conditions occur. The single germination of $A$. robusta from the investigation can lead to the presumption that temperature may influence germination. The temperature in cooler winter rainfall areas of Australia can decrease germination if a sudden temperature increase occurs (Cochrane 2020). Making this presumption based on the evidence of single germination of $A$. robusta may seem somewhat unreliable.

From investigation $A$. robusta recruitment a species with woody aggregate fruit, demonstrating serotinous species' traits should positively correlate with fire. From the investigation, only a single germinant of $A$. robusta occurred, having a woody aggregate fruit is not the only trait that would define a species as fire tolerant. Tangney et al. (2020) identified that besides having fruit that protects the seed from fire is only part of the equation, and the other is survival at higher temperatures. Tangney et al. (2020) explain that the aggregate fruit's role is to protect the seed from lethal temperatures, allowing seed release to occur from the aggregate fruit. The aspect of the lethal temperatures to seed occurred in a previous investigation where the thickness of the seed lens dictated the survivability of a seed when exposed to fire (Herranz et al. 1998). The relationship between heat and germination between some serotinous species occurred through an investigation by Roeder et al. (2019). Roeder et al. (2019) and Luna (2020) establishes that the length of time a seed exposed to heat will reflect the seed survival. For instance, a fire with high intensity can reduce the survival of seed woody aggregate capsules (Roeder et al. 2019). Tangney et al. (2020) explain that serotiny is composed of several traits to identify if a species is fire tolerant. Seeds with a thinner lens have lower survivorship from fire (Herranz et al. 1998; Luna 2020). The aggregate fruit may protect the $A$. robusta seed from fire as alterative to a thicker seed lens. In the investigation, the assumption made that seed released from sensing individuals. Based on the investigation from Herranz et al. (1998) the seed without the protection of the aggregate fruit may not survive.

Tangney et al. (2020) describe the physical traits (phenotypes) for classifying a species according to fire tolerance supports the review conducted by Lamont and Bellingham (2020) who describes that genotypes can be reflective of fire tolerance. (Lamont and Bellingham 2020) cites an example of the same species in different communities expressing different degrees of fire tolerance. The differences a single species can have in fire tolerance occurred through phenotype regulation from environmental stressors (Lamont and Bellingham 2020). From the current investigation, the lack of $A$. robusta germinants is partially supportive of the Lamont and Bellingham (2020) review of serotiny. Lamont and Bellingham (2020) do not discount the role of environmental factors contributing to communities that exhibit fire tolerance. For A. robusta, understanding the role of fire on the aggregate is considered necessary to determine the species' degree of serotiny. The concept of the degree of serotiny exhibited by species can be related to the review undertaken by Lamont and Bellingham (2020).

Lamont and Bellingham (2020) developed a model that indicates the degree of serotiny over time; the aspect of serotiny in A. robusta considered in Pearson (2020). From the investigation, a single seedling of A. robusta occurred, which raises several questions on the degree of serotiny in A. robusta. Determining the degree of serotiny A. robusta can occur through using Lamont and Bellingham (2020). The results from the current investigation would indicate that $A$. robusta is possibly not a serotinous species. Baskin and Baskin (2019) indicate that parental species influence seed germination to maintain the species existence. The paternal role of the parent indicated it might influence the genotype of the offspring. Extending the parental effect concept could form the species heritable traits (Lamont et al. 2020). The relationship that offspring and parents, according to Lamont et al. (2020) have been rarely studied. Lamont et al. (2020) demonstrate that serotiny is a herdable trait, but fire can be a selective tool for defining which species will form the community. The A. robusta samara seed would potentially move away from the parent plant by the wind. Rehounková et al. (2020) described the targeted species seed, which moved into the clear areas had an increase in germination. The same concept needs testing with $A$. robusta to determine if germination increases in the parent plant's absence. The structure of the community would be reflective of the fire return interval. As the interval between a fire needs to be long enough for a species to germinate, reach a stage of maturity to set seed before the next fire (Lamont et al. 2020). The point made by Lamont et al. (2020) can be applied to A. robusta in as 
far as understanding the parental effects on A. robusta seed recruitment and what level of serotiny does $A$. robusta have concerning fire.

Reflecting on the study's aim was to test the effect of an ecological burn on A. robusta by determining if latent soil seed bank supports seed recruitment of A. robusta. The results provided no conclusive answer; the study provides future avenues to consider the role of seed dormancy in $A$. robusta, the first step as Mackenzie et al. (2016) describes is to test and overcome the actual cues which will promote seed recruitment. Even though germination of seed regularly occurs in horticultural environments, the same may not be accurate for natural conditions (Mackenzie et al. 2016). From the pilot study, an underlying assumption occurred on competition between individuals in the seed bank. The assumption was that all individuals had an equal chance of germination and survival without competition. Catterall (2020) explains with a modified ecological community; the competition would be higher in the nonnative species and the rudimental native species. The aspect of competition between seedlings can impact management strategies selected for regeneration for $A$. robusta. Catterall (2020) offers some possible strategies for reverting agriculture to a regenerated native community. Competition from other species would impact the $A$. robusta ability to regenerate, the other aspect discussed by Baskin and Baskin (2019) is the parent plant's role. Baskin and Baskin (2019) describe that maternal inflorescences can impact the soil's seed bank germination. The paternal relationship to the seed could occur through the seeds genotype (Baskin and Baskin 2019). These are avenues that would require further exploration to understand what may limit the natural seed recruitment of $A$. robusta.

Knowing where genetics would fit into these concepts can be seen as a possible area to investigate in the future. Understanding restoration practices and knowing how they could initiate natural seed recruitment strategies is vital (Catterall 2020). A. robusta position in the current landscape modified from agriculture (Bickford and Mackey 2004; Bickford et al. 2008). To restore fragmented communities of $A$. robusta a near undisturbed reference site required (Walpole et al. 2020). The reference site's purpose would indicate the degree of change in these sites and a level of resilience and responsiveness to facilitate recovery (Walpole et al. 2020). The difficulty in the restoration as Walpole et al. (2020) identified public perception of what the vegetation community was like before human disturbance can impact the project's success. Having a reference site to work from would be critical for the recovery of $A$. robusta as this would provide insight into how to simulate natural recruitment in the fragmented populations.

In conclusion, from the pilot study, it appears that $A$. robusta populations may not be recruiting to the population and would struggle to persist in the long term due to a lack of seed recruitment. A reliance on lignotubers for persistence may develop. The consideration of the role of lignotuber did not occur as part of the present study. However, long term survival requires seed recruitment as a necessary part of a future recruitment strategy. Serotinous species like A. robusta, where the role of fire could trigger the natural recruitment of the next generation need further investigation. These future investigations should focus on cues needed for stimulating seed recruitment. Fire is part of the process; the management practices used need investigating further to ensure long-term population survival.

\section{ACKNOWLEDGEMENTS}

Thank you to Dr. R. J-P Davis for assistance in the project's conceptual idea and assistance when undertaking the initial fieldwork. The authors declare no conflict of interest in the investigation design and implementation. No third-party involvement occurred with data collection and analyses.

\section{REFERENCES}

Abbott I. 1984. Emergence, early survival, and growth of seedlings of six tree species in Mediterranean forest of Western Australia. For Ecol Manag 9 (1): 51-66.

Addinsoft. 2017. XLSTAT Ecol. New York (United States of America), Addinsoft Inc. 3.

Alahakoon AACB, Perera GAD, Merritt DJ, Turner SR, GamaArachchige NS. 2020. Species-specific smoke effects on seed germination of plants from different habitats from Sri Lanka. Flora 263: DOI: 10.1016/j.flora.2019.151530.

Armstrong DM, Brandle R, Croft SJ, Queale L, Smith F, Goonan P, McEvoy P, Madden C, McArthur A, Hirst D, Reardon T. 2003. A Biological Survey of the Southern Mount Lofty Ranges, South Australia, 2000-2001. Endeavour Print Digital, Adelaide (Australia).

Bachmann M, Farrington L. 2016. Hydrological restoration options for Glenshera Swamp, Stipiturus Conservation Park: A case study for investigating the feasibility of restoring the water regime of Fleurieu Peninsula swamps impacted by artificial drainage. Department of Environment Water and Natural Resources. Nature Glenelg Trust, Mt Gambier, SA, Australia,

Baskin JM, Baskin CC. 2019. How much influence does the paternal parent have on seed germination? Seed Sci Res 29 (1): 1-11.

Beinke S, Clayton S, Ellis R, Prescott A, Richardson K, Slipper M, Stephens B, Tanner I, Tilley J, Turner J. 2011. Operational prescriptions field guide: Prescribed burning in South Australia. South Australia Fire Management Branch/Regional Conservation, Adelaide, Australia.

Bickford S, Gell P, Hancock GJ. 2008. Wetland and terrestrial vegetation change since European settlement on the Fleurieu Peninsula, South Australia. The Holocene 18 (3): 425-436.

Bickford S, Mackey B. 2004. Reconstructing pre-impact vegetation cover in modified landscapes using environmental modelling, historical surveys and remnant vegetation data: A case study in the Fleurieu Peninsula, South Australia. J Biogeography 31 (5): 787-805.

Bradford G, Finney S, He Y, Manou M. 2008. Myponga Watercourse Restoration Project final report 2000-07. Environment Protection Authority. Environment Protection Authority, Adelaide, SA, Australia.

Catterall CP. 2020. Influencing landscape-scale revegetation trajectories through restoration interventions. Curr Landsc Ecol Rep 5 (4): 116126.

Chick MP, Nitschke CR, Cohn JS, Penman TD, York A, Tanentzap A. 2018. Factors influencing above-ground and soil-seed bank vegetation diversity at different scales in a quasi-Mediterranean ecosystem. J Veg Sci 29 (4): 684-694.

Cochrane A. 2020. Temperature thresholds for germination in 20 shortrange endemic plant species from a Greenstone Belt in southern Western Australia. Plant Biol 22 (Suppl 1): 103-112.

Cortina J, Maestre FT. 2005. Plant Effects on Soils in Drylands: Implications for Community Dynamics and Ecosystem Restoration. 
In: Binkley D, Menyailo O (eds.). Tree Species Effects on Soils: Implications for Global Change. Netherlands, Springer.

Department for Environment and Heritage. 2007. Stipiturus Conservation Park Management Plan. Department for Environment and Heritage, Adelaide, SA, Australia.

Dias LS, Pereira LP, Soveral Dias A. 2019. Seed germination in Cistus ladanifer: Heat shock, physical dormancy, soil temperatures and significance to natural regeneration. Plants 8: 3 . DOI: 3390/plants8030063.

Finlay CMV, Bradley CR, Preston SJ, Provan J. 2017. Low genetic diversity and potential inbreeding in an isolated population of alder buckthorn (Frangula alnus) following a founder effect. Sci Rep 7 (1) 3010. DOI: $10.1038 / \mathrm{s} 41598-017-03166-1$.

Gtinster A. 1994. Seed bank dynamics m longevity, viability and predation of seeds of serotinous plants in the central Namib Desert. J Arid Environ 28 (3): 195-205.

Herranz JeM, Ferrandis P, Martinez Sanchez JJ. 1998. Influence of heat on seed germination of seven Mediterranean Leguminosae species. Plant Ecol 136 (1): 95-103

Hodges JA, Price JN, Nimmo DG, Guja LK. 2019. Evidence for direct effects of fire-cues on germination of some perennial forbs common in grassy ecosystems. Austral Ecol 44 (7): 1271-1284.

Jessop J, Toelken H. 1986. Flora of South Australia; Part I, Lycopodiaceae-Rosaceae. South Australian Government Printing Division, Adelaide, SA, Australia.

Lamont, BB, Bellingham P. 2020. Evaluation of seven indices of on-plant seed storage (serotiny) shows that the linear slope is best. J Ecol. DOI: $10.1111 / 1365-2745.13436$

Lamont BB, Pausas JG, He T, Witkowski ETF, Hanley ME. 2020. Fire as a selective agent for both serotiny and non-serotiny over space and time. Crit Rev Plant Sci 39 (2): 140-172.

Le Breton TD, Natale S, French K, Gooden B, Ooi MKJ. 2019. Fireadapted traits of threatened shrub species in riparian refugia: implications for fire regime management. Plant Ecol 221 (1): 69-81.

Luna B. 2020. Fire and summer temperatures work together breaking physical seed dormancy. Sci Rep 10 (1): 6031. DOI: 10.1038/s41598020-62909-9

Ma M, Baskin CC, Yu K, Ma Z, Du G. 2017. Wetland drying indirectly influences plant community and seed bank diversity through soil $\mathrm{pH}$. Ecol Indicat 80: 186-195

Mackenzie BDE, Auld TD, Keith DA, Ooi MKJ. 2016. How fire an seasonal temperatures influence the germination of many plant species: insights from Boronia (Rutaceae). Australasian Plant Conserv 25 (2): 5-7.

Morgan GW, Tolhurst KG, Poynter MW, Cooper N, McGuffog T, Ryan R, Wouters MA, Stephens N, Black P, Sheehan D, Leeson P, Whight S, Davey SM. 2020. Prescribed burning in south-eastern Australia: history and future directions. Austr For 83 (1): 4-28.
Ooi MKJ, Auld TD, Whelan RJ. 2007. Distinguishing between persistence and dormancy in soil seed banks of three shrub species from fireprone south-eastern Australia. J Veg Sci 18 (3): 405-412.

Pearson MW. 2020. A case study of Allocasuarina robusta recovery using history and biogeography to identify future priorities. J Resour Ecol 11 (2): 171-181.

Quarmby J. 2016. Action Plan for Mount Compass Oak-bush (Allocasuarina robusta). Nature Conservation Society of South Australia, Adelaide, Australia.

R Development Core Team. 2010. R: A Language and Environment for Statistical Computing Reference Index. R Foundation for Statistical Computing, Vienna, Austria. https://www.r-project.org/.

Řehounková K, Jongepierová I, Šebelíková L, Vítovcová K, Prach K. 2020. Topsoil removal in degraded open sandy grasslands: can we restore threatened vegetation fast? Restor Ecol. DOI: $10.1111 /$ rec. 13188

Roeder M, Yang W, Tomlinson K. 2019. Influence of smoke, heat and fire on germination of woody species occurring in the dry valleys of southwest China. J Plant Ecol 12 (6): 931-940.

Sagra J, Moya D, Plaza-Álvarez PA, Lucas-Borja ME, González-Romero J, De las Heras J, Alfaro-Sánchez R, Ferrandis P. 2019. Prescribed fire effects on early recruitment of Mediterranean pine species depend on fire exposure and seed provenance. For Ecol Manag 441: 253-261.

Saverimuttu T, Westoby M. 1996. Seedling longevity under deep shade in relation to seed size. J Ecol 84 (5): 681-689.

Tangney R, Merritt DJ, Callow JN, Fontaine JB, Miller BP. 2020. Seed traits determine species responses to fire under varying soil heating scenarios. Funct Ecol 34 (9): 1967-1978.

Walpole EH, Toman E, Stidham M, Wilson R. 2020. The science and practice of ecological restoration: a mental models analysis of restoration practitioners. Environ Syst Decis 40 (4): 588-604.

Wellington AB, Noble IR. 1985. Seed dynamics and factors limiting recruitment of the Mallee Eucalyptus incrassata in semi-arid, southeastern Australia. J Ecol 73 (2): 657-666.

Wills TJ, Read J. 2002. Effects of heat and smoke on germination of soilstored seed in a south-eastern Australian sand heathland. Austr J Bot 50 (2): 197-206.

Wilson KL, Johnson LAS. 1989. Casuarinaceae. In: George AS, Telford IRH, Thompson HS (eds.) Flora of Australia Hamamelidales to Casuarinales 3: 165-166. Australian Government Printer, Canberra ACT, Australia.

Woolfrey AR, Ladd PG. 2001. Habitat preference and reproductive traits of a major Australian riparian tree species (Casuarina cunninghamiana). Austr J Bot 49 (6): 705-715.

Zirondi HL, Silveira FAO, Fidelis A. 2019. Fire effects on seed germination: Heat shock and smoke on permeable vs impermeable seed coats. Flora 253: 98-106 